ORIGINAL ARTICLE

\title{
Visual failure without headache in idiopathic intracranial hypertension
}

\author{
M Lim, M Kurian, A Penn, D Calver, J-P Lin
}

Arch Dis Child 2005;90:206-210. doi: 10.1136/adc.2003.039305

See end of article for authors' affiliations

.....................

Correspondence to: Dr J-P Lin, Department of Paediatric Neurology, Guy's \& St Thomas' Hospitals NHS Trust, 11 th Floor, Guys Tower, St Thomas' Street, London SEI 9RT, UK; jeanpierrelin@aol.com

Accepted 13 June 2004

\begin{abstract}
Aim: To determine the differences in outcome in a group of children with idiopathic intracranial hypertension $(\mathrm{IIH})$ who do not present with headaches.

Methods: Differences in epidemiological and aetiological factors, clinical presentation, and visual outcome were investigated in children with a diagnosis of $\mathrm{IH}$ presenting with and without headaches to the Paediatric Neurology and Paediatric Ophthalmology Services at Guy's \& St Thomas' Hospitals NHS Trust between 1997 and 2002.

Results: Compared to the 29 children with headaches, the 12 children in the non-headache group were younger ( $7.3 v 9.5$ years), presented with more neurological signs (33\% v 10\%), and were more likely to present with severe visual failure $(33 \% \vee 4 \%)$, with a tenfold increased risk of an enlarged blind spot or field defects $(50 \% \vee 5 \%)$. Permanent visual failure affected a third of all children in the non-headache group, but was rare in children presenting with headaches $(33 \% \vee 3 \%)$, with one patient registered blind and two severely visually impaired.

Conclusion: The management of IH is difficult in the absence of headache. Visual surveillance is vital. These children were treated with an aggressive management programme to reduce cerebrospinal fluid pressure by repeated lumbar puncture, medication, and early surgical intervention if required. Noninvasive monitoring techniques might contribute to a better understanding of the natural history of $I \mathrm{H}$, improved management, and visual outcome.
\end{abstract}

diopathic intracranial hypertension (IIH) presents commonly as a headache syndrome characterised by raised cerebrospinal fluid (CSF) pressure in the absence of an intracranial mass lesion or ventricular dilatation. IIH is usually associated with a normal level of consciousness, papilloedema, and occasional 6th nerve palsy with an otherwise normal neurological examination. The CSF pressure is by definition raised, but chemical and cellular composition is normal. This forms the basis of the modified Dandy criteria for the diagnoses of $\mathrm{IIH} .{ }^{1}$ Benign intracranial hypertension and pseudotumour cerebri are other names ascribed to this condition. Lessell has discussed disagreements among experts on the definition and the "correct" nomenclature in a major review of this condition in childhood ${ }^{2}$ In a reappraisal of the condition by Digre and Corbett, ${ }^{3}$ the merits of a clinical approach to diagnose a "primary" or idiopathic form where no cause is found and a "secondary" non-space occupying form, is discussed. This alerts the clinician to actively treat the "secondary" causative factors (for example, dural sinus thrombosis), while the approach to pressure lowering remains similar in both groups. Whether the "secondary group" form a subgroup within "idiopathic" intracranial hypertension is debatable, but a consensus is required for comparison of future studies and therapeutic trials.

IIH is not uncommon in childhood and has been reported in earlier historical series ${ }^{45}$ prior to the publication of two major series devoted to childhood IIH. ${ }^{6} 7$ Subsequent reports have highlighted the changing clinical picture over time, with less of an emphasis on the "otitic" form ${ }^{8}$ and the unravelling of further aetiological associations with this condition, both in children and in adults. ${ }^{2}$ Recent reports ${ }^{9-11}$ have characterised the long term visual complication in children, highlighting a change from earlier observations of a relatively good visual outcome in childhood IIH. ${ }^{6}{ }^{12-16}$ Youth does not confer a protective effect on vision. More aggressive medical and surgical treatment with closer CSF pressure monitoring is advocated, but the efficacy of these interventions remains to be fully evaluated.

The two features of IIH, headache and papilloedema, do not always occur together. Headaches without papilloedema due to raised intracranial pressure from measurement of CSF pressure have been reported. ${ }^{17}{ }^{18}$ Presentations of papilloedema without headaches have been reported in series where patients were either too young to complain of headaches ${ }^{21}$ or in cases where headaches were frankly absent. ${ }^{7}{ }^{19}$

In this study, we report differences in epidemiological and aetiological factors, clinical presentation, investigations, and initial and longer term visual failure in 12 children with IIH presenting without headaches.

\section{PATIENTS AND METHODS}

All children under 16 presenting to the Paediatric Neurology and Ophthalmology Department at Guy's \& St Thomas' Hospitals NHS Trust with a diagnosis of IIH between 1997 and 2002 were entered in this retrospective and prospective (from year 2000) cohort study. Criteria for inclusion in the study included the presence of papilloedema and/or headaches; a raised CSF pressure $\left(>20 \mathrm{~cm} \mathrm{H}_{2} \mathrm{O}\right)$ measured by lumbar puncture with normocarbia (3.5-5.5 $\mathrm{KPa} \mathrm{CO}_{2}$ ) confirmed during the procedure; normal CSF analysis; the absence of ventriculomegaly or mass lesion on neuroimaging; and at least six months of neurological and ophthalmological follow up. We have followed the convention of previous publications in the field of including "secondary" cases of IIH.

Patients were excluded from the study if deemed by ML or JPL not to have undergone adequate assessment as outlined

Abbreviations: CSF, cerebrospinal fluid; IIH, idiopathic cranial hypertension; MRI, magnetic resonance imaging; MRV, magnetic resonance venography 
Table 1 Comparison of epidemiological, aetiological, and investigative data

\begin{tabular}{lll}
\hline & $\begin{array}{l}\text { Headache } \\
(\mathbf{n}=\mathbf{2 9})\end{array}$ & $\begin{array}{l}\text { Non-headache } \\
(\mathbf{n}=\mathbf{1 2})\end{array}$ \\
\hline $\begin{array}{l}\text { Mean age in years } \\
\text { (95\% Cl) }\end{array}$ & 9.5 & 7.3 \\
(Median) & $(1.4)$ & $(2.3)$ \\
Mean follow up time in months & $(10)$ & $(6.5)$ \\
Male:female & 30 & 32 \\
Associated risk factors (\%) & $13: 16$ & $5: 7$ \\
Mean CSF opening & $18(62 \%)$ & $8(66 \%)$ \\
pressure in cm $\mathrm{H}_{2} \mathrm{O}$ & & \\
(95\% Cl) & 33.2 & 31.4 \\
(Median) & $(4.9)$ & $(3.4)$ \\
\hline
\end{tabular}

by Soler and colleagues, ${ }^{20}$ or until such was completed. This included a full neurological assessment by a member of the paediatric neurology team; a detailed visual acuity attempted in the over 3 year olds and assessment of visual fields by Goldmann perimetry in the over 7 year olds; ophthalmic assessment by DC including ultrasound of orbits to exclude optic nerve head drusens if clinically indicated; brain magnetic resonance imaging (MRI) and magnetic resonance venography (MRV) of the dural venous sinuses. Further investigations were tailored to the patient history and clinical assessment. It remains the practise of the department to use acetazolamide as first line treatment, adding frusemide and/ or steroids in the unresponsive patient or those intolerant to acetazolamide.

Forty one patients were identified and medical notes were reviewed to compare epidemiological and aetiological factors, clinical presentation, investigative findings, initial and longer term visual failure, and response to therapy in both groups of patients presenting with and without headaches.

Statistical analysis was performed on an SPSS package (version 10) with non-parametric $\chi^{2}$ tests employed.
Table 2 Comparison of aetiology

\begin{tabular}{|c|c|c|}
\hline & $\begin{array}{l}\text { Headache } \\
(n=29)\end{array}$ & $\begin{array}{l}\text { Non-headache } \\
(n=12)\end{array}$ \\
\hline $\begin{array}{l}\text { Ear, nose, and } \\
\text { throat (ENT) }\end{array}$ & $\begin{array}{l}6(21 \%) \\
1 \text { transverse sinus } \\
\text { thrombosis }\end{array}$ & $4(33 \%)$ \\
\hline Viral infection & 0 & $1(8 \%)$ \\
\hline Overweight & $5(17 \%)$ & $1(8 \%)$ \\
\hline Medication & $3(10 \%)$ & $1(8 \%)$ \\
\hline \multirow[t]{5}{*}{ Others } & $8(28 \%)$ & $1(8 \%)$ \\
\hline & $\begin{array}{l}4 \text { post-renal } \\
\text { transplant }\end{array}$ & $\begin{array}{l}\text { Raised antistreptococcal } \\
\text { titre }\end{array}$ \\
\hline & $\begin{array}{l}1 \text { cardiac and small } \\
\text { vessel disease }\end{array}$ & \\
\hline & 1 sinus venous thrombosis & \\
\hline & $\begin{array}{l}1 \text { inflammatory } \\
\text { bowel disease } \\
1 \text { collagen disease }\end{array}$ & \\
\hline \multirow[t]{2}{*}{ None found } & $11(38 \%)$ & $4(33 \%)$ \\
\hline & & 3 routine eye screening \\
\hline
\end{tabular}

\section{RESULTS}

Twenty nine patients were identified in the headache group and 12 in the non-headache group. Table 1 summarises the epidemiological, aetiological, and investigative data. Table 2 details the various aetiological associations in both groups. More patients in the non-headache group had ear infections. In this group, two patients had chronic ear infections with no evidence of dural sinus thrombosis on neuroimaging.

Table 3 summarises the visual symptoms and signs. In the headache $(n=3)$ and non-headache $(n=1)$ group, patients who did not have papilloedema had MRI features of raised intracranial pressure (dilated perioptic nerve sheaths and empty sella), prompting CSF pressure monitoring. The visual outcome of patients in the non-headache group was significantly worse $(p=0.008)$ than in patients with headaches (table 4). In the non-headache group, one patient was registered blind and two as severely visually impaired. One

Table 3 Visual and neurological assessment at presentation

\begin{tabular}{|c|c|c|c|}
\hline & $\begin{array}{l}\text { Headache } \\
(n=29)\end{array}$ & $\begin{array}{l}\text { Non-headache } \\
(n=12)\end{array}$ & $p$ value \\
\hline Visual symptoms & $12(41 \%)$ & $5(42 \%)$ & NS \\
\hline Papilloedema & $26(90 \%)$ & $\begin{array}{l}11(92 \%) \\
2 \text { patients presenting } \\
\text { with macular stars }\end{array}$ & NS \\
\hline Enlarged blind spot/number able to test & $1 / 20(5 \%)$ & $4 / 8(50 \%)$ & 0.02 \\
\hline $\begin{array}{l}\text { Visual failure (vision } 6 / 36 \text { or worse in either eye)/ } \\
\text { number able to test }\end{array}$ & $1 / 26(4 \%)$ & $4 / 12(33 \%)$ & 0.02 \\
\hline Cranial nerve palsies & $3 / 29(10 \%)$ & $4 / 12(33 \%)$ & 0.076 \\
\hline
\end{tabular}

Table 4 Comparison of visual outcome

\begin{tabular}{llll}
\hline & $\begin{array}{l}\text { Headache } \\
(\mathbf{n = 2 9 )}\end{array}$ & $\begin{array}{l}\text { Non-headache } \\
(\mathbf{n}=12)\end{array}$ & p value \\
\hline Resolved & $8(28 \%)$ & $8(66 \%)$ & 0.02 \\
On treatment (asymptomatic) & $16(55 \%)$ & $3(25 \%)$ & NS \\
On treatment (symptomatic) & $5(17 \%)$ & $1(8 \%)$ & NS \\
Surgical interventions & 2 & 1 & NS \\
Visual failure (vision of worse & $1(3 \%)$ & Optic nerve fenestration & 0.008 \\
than 6/36 in either eye) & & $4(33 \%)$ & \\
\hline
\end{tabular}




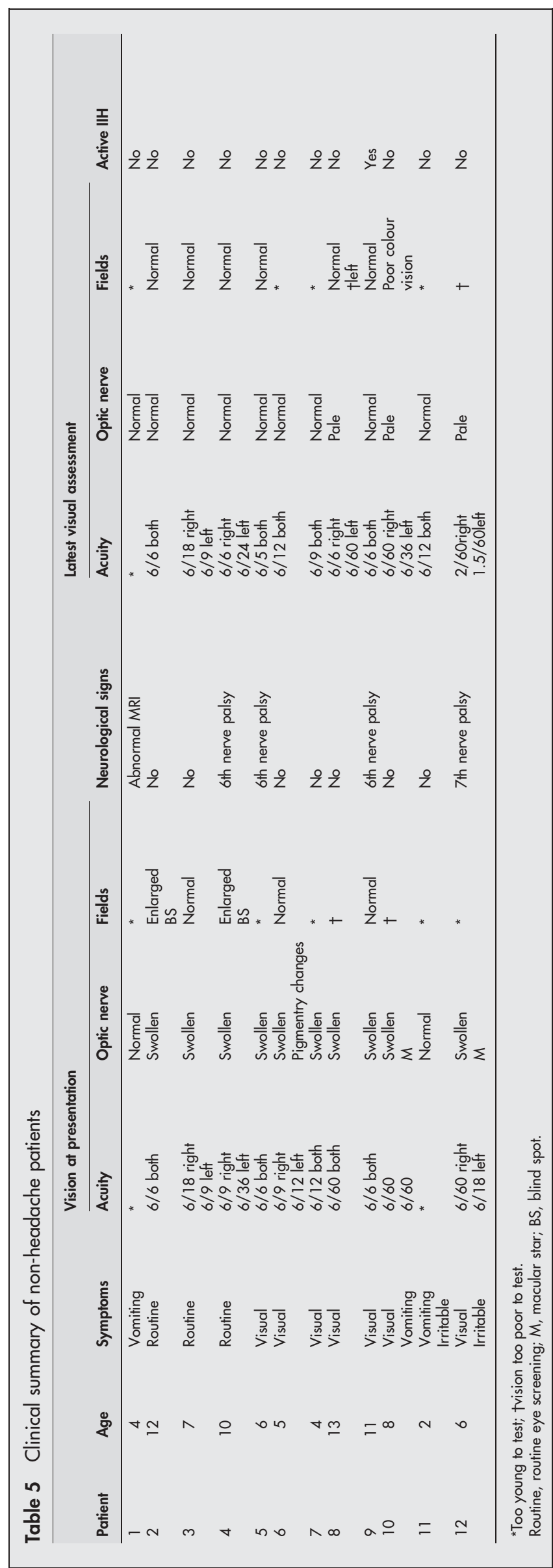

patient who was registered blind and one with severe visual impairment presented with macula stars. Table 5 provides further clinical details of the non-headache group.

\section{DISCUSSION}

\section{Non-headache presentation}

Idiopathic intracranial hypertension without headaches has been described in the literature. In infancy, somnolence apathy or irritability can be the presenting symptom, as in the younger child (two in our series) who may not be able to articulate his or her headache but instead presents with irritability. ${ }^{2}$ Occasionally papilloedema is discovered incidentally on routine eye screening. ${ }^{719}$ Three of our patients were identified on routine examination prompted by poor spelling at school, family history of retinitis pigmentosa, and prematurity. Other patients in this group had either visual or neurological symptoms that warranted further assessment. The reason for these patients not having headache is unclear as opening CSF pressures were comparable to those of the headache group (table 1). Ventricular compliance and duration of raised pressure may play a role in understanding clinical differences.

The proportion of patients who present without headaches in our patient group (29\%) is higher than in recent series. ${ }^{25} 26$ Earlier series ${ }^{78}$ described headaches in about $60 \%$ of patients and comprised a larger proportion of young infants with the "otitic" form of IIH who were unable to complain of headache. Hospital series like ours are prone to ascertainment bias, as many of the typical cases would have been managed by the local paediatric services in our region.

\section{Visual failure}

Loss of acuity, reduced colour vision, restricted visual fields, and an increased blind spot are the only serious permanent complications of IIH, although headaches can be disruptive to life. Lessell first reported a paediatric series with permanent visual impairment following IIH. ${ }^{9}$ Baker et al reviewed the literature in $1989^{11}$ and found six paediatric studies (seven publications) ( $^{12-16}$ before 1985 that reported a total of 185 patients and described visual loss in only four patients $(2 \%)$. Two patient series $^{810}$ after 1985 reported a total of $14 / 60$ patients $(23 \%)$ with visual impairment. This strongly challenged the view that vision was spared in the paediatric IIH population. The reason for this change in phenotype remains unclear. It is important to make a distinction between visual failure at presentation and longer term permanent visual failure. Paediatric series have shown visual failure at presentation (loss of visual acuity, enlarged blind spot of visual field defects alongside papilloedema) to range between $16-62 \%$, and permanent visual failure in 0 $19 \%$ (table 6). Case series and cohorts sampled from different specialties make generalisation of data extremely difficult. An ophthalmology department will have an abnormal weighting of patients with visual failure.

Both patients presenting with macular stars had severe visual failure at follow up. The reason for severe visual failure in this group of children is unknown. Headaches may act as a warning signal and protect vision. However, our patients in the non-headache group had a more rapid resolution of pressure (table 4). Furthermore, the time from symptom onset to treatment did not differ in either group (data not shown). A concurrent inflammatory process (neuritis) is a credible but speculative explanation for visual failure in the absence of recent infection or raised inflammatory markers.

\section{Management of the non-headache group}

Children without headache or warning symptoms of high intracranial pressure are a challenge to manage. Deterioration of vision is not an acceptable monitoring tool. Urgent and 
Table 6 Comparison of visual outcome in various paediatric series

\begin{tabular}{|c|c|c|c|}
\hline First author & Patients & $\begin{array}{l}\text { Visual loss at } \\
\text { presentation* } \dagger\end{array}$ & Permanent visual loss ${ }^{\dagger} \dagger$ \\
\hline Baker review of pre-1985 cases 9 & 185 & & $2 \%$ \\
\hline Baker, $1985^{10}$ & 36 & $30 \%$ & $\begin{array}{l}16 \% \\
3 \% \text { severe }\end{array}$ \\
\hline $\begin{array}{l}\text { Couch, } 1985^{7} \\
\text { Lessell, } 1985^{8}\end{array}$ & $\begin{array}{r}24 \\
5\end{array}$ & $16 \%$ & $\begin{array}{l}8 \% \text { severe loss } \\
100 \% \neq\end{array}$ \\
\hline Babikian, $1992^{20}$ & 30 & $20 \%$ & $3 \%$ \\
\hline Cinciripini, $1998^{21}$ & 10 & $60 \%$ & $10 \%$ severe \\
\hline Phillips, $1998^{22}$ & 35 & $40 \%$ & $\begin{array}{l}19 \% \\
10 \text { patients with optic } \\
\text { atrophy }\end{array}$ \\
\hline Youroukos, $2000^{23}$ & 36 & $28 \%$ & $6 \%$ \\
\hline Salman, $2001^{24}$ & 32 & $38 \%$ & $\begin{array}{l}9 \% \\
3 \% \text { severe }\end{array}$ \\
\hline Kesler, $2002^{25}$ & 27 & $62 \%$ & $0 \%$ \\
\hline
\end{tabular}

Severe visual loss defined as worse than $6 / 60$ (or 20/200) loss in either eye.

${ }^{*}$ Defined as either decreased visual acuity or field defect.

tPercentage taken over total number of patients even when visual data not available.

flessell reported a series with poor visual outcome.

aggressive treatment with medical and surgical management strategies until lowering of pressure is confirmed is required. Paediatric practice demands minimising discomfort to children, so that lumbar punctures (often repeated) are performed under general anaesthesia. The physiological effect of hypercarbia on intracranial pressure is recognised in the intensive care and anaesthetic settings. It has been shown in adults with IIH that hyperventilation lowers intracranial pressure at lumbar puncture. ${ }^{27}$ We have shown that a rise of end-tidal $\mathrm{pCO}_{2}$ by $1 \mathrm{KPa}$ causes a rise of CSF pressure by $3.5-12 \mathrm{~cm} \mathrm{H}_{2} \mathrm{O}$ (mean $7 \mathrm{~cm} \mathrm{H}_{2} \mathrm{O}$ ) in children with IIH (Lim and Lin, unpublished observations). Controlling $\mathrm{pCO}_{2}$ is therefore important when measuring CSF pressure to prevent misdiagnosis and over-treatment of patients with "spurious IIH" induced by the anaesthesia and for monitoring the effects of medical management. Other factors that can increase intracranial pressure, including positioning and anaesthetic agents, also require consideration.

Surgical options need to be considered early in the headache and non-headache group with visual failure, in whom medical measures have failed and the symptoms can only be managed with repeated lumbar puncture. The choice between optic nerve fenestration and lumboperitoneal shunting or both remains unresolved as exemplified by an adult series in which optic nerve fenestration was required before or after lumboperitoneal shunting to relieve pressure on the optic nerve. ${ }^{28}$ Vital decision making still depends on accurate measurements of the CSF pressure. Evaluation of optic disc swelling with high resolution ultrasonography ${ }^{29}$ and confocal laser ophthalmoscopy ${ }^{30}$ may provide extra tools to monitor the degree of optic disc swelling, although the severity of disc oedema has not consistently been related to visual loss in adults, ${ }^{29}{ }^{31}{ }^{32}$ and remains to be evaluated in children.

\section{Conclusion}

Children with IIH without headaches, have more neurological signs and visual failure on presentation. Their long term visual outcome is also poorer, especially in association with macular stars at presentation. The only treatment option remains aggressive reduction of CSF pressure by repeated lumbar puncture, medication, and early surgical intervention. Long term visual surveillance is vital. Reliable non-invasive ways of monitoring CSF are urgently required in the clinical setting to monitor progress and inform management.

\section{ACKNOWLEDGEMENTS}

We would like to thank the paediatric day care team, anaesthetic department, and paediatric orthoptists at Guy's Hospital NHS Trust for their invaluable help in managing the patients. We are grateful to our paediatric neurology and paediatric colleagues in the South Thames Region, UK for patient referrals to the combined Paediatric Neurology and Ophthalmology clinic.

\section{Authors' affiliations}

M Lim, M Kurian, A Penn, J-P Lin, Department of Paediatric Neurology, Guy's \& St Thomas' Hospitals NHS Trust, London, UK

D Calver, Paediatric Ophthalmology Department, Guy's \& St Thomas' Hospitals NHS Trust, London, UK

Competing interests: none declared

\section{REFERENCES}

1 Wall M. Idiopathic intracranial hypertension. Neurol Clin 1991;9:73-95.

2 Lessell S. Paediatric pseudotumour cerebri (idiopathic intracranial hypertension). Surv Ophthalmol 1992;37:155-66.

3 Digre KB, Corbett JJ. Idiopathic intracranial hypertension (pseudotumour cerebri): a reappraisal. Neurologist 2001;7:2-67.

4 Davidoff LM. Pseudotumour cerebri: benign intracranial hypertension. Neurology 1956;6:605-15.

5 Foxley J. Benign forms of intracranial hypertension - "toxic" and "otitic" hydrocephalus. Brain 1955;78:1-41.

6 Rose A, Matson DD. Benign intracranial hypertension in children. Paediatrics 1967;39:227-37.

7 Grant DN. Benign intracranial hypertension-a review of 79 cases in infancy and childhood. Arch Dis Child 1971;46:651-5.

8 Couch R, Camfield PR, Tibbles JAR. The changing picture of pseudotumour cerebri in children. Can J Neurol Sci 1985;12:48-50.

9 Lessell S, Rosman P. Permanent visual impairment in childhood pseudotumour cerebri. Arch Neurol 1985;43:801-4.

10 Baker RS, Carter D, Hendrick EB, et al. Visual loss in pseudotumour cerebri of childhood. Arch Ophthalmol 1985;103:1682-6.

11 Baker R, Baumann R, Bunic JR. Idiopathic intracranial hypertension (pseudotumour cerebri) in paediatric patients. Paediatr Neurol 1989:5(1):5-11.

12 Greer M. Benign intracranial hypertension I. Mastoiditis and lateral sinus obstruction. Neurology 1962;12:472-6.

13 Greer M. Benign intracranial hypertension: II. Following corticosteroid therapy. Neurology 1963;13:439-41

14 Hagberg B, Sillanpaa M. Benign intracranial hypertension (pseudotumour cerebri). Acta Paediatr Scand 1970;59:328-9.

15 Weisberg LA, Chutorian AM. Pseudotumour cerebri of childhood. Am J Dis Child 1977;131:1243-8.

16 Sneazy J, Paraicz E. Benign intracranial hypertension of uncertain origin Acta Paediatr Hung 1979;20:285-90.

17 Amacher AL, Spence JD. Spectrum of benign intracranial hypertension in children and adolescents. Childs Nerv Syst 1985;1:81-5.

18 Wraige $\mathrm{E}$, Chandler $\mathrm{C}$, Pohl K. Idiopathic intracranial hypertension: is papilloedema inevitable? Arch Dis Child 2002;87:223-4.

19 Weig SG. Asymptomatic idiopathic intracranial hypertension in young children. J Child Neurol 2002;17:239-41.

20 Soler D, Cox T, Bullock $P$, et al. Diagnosis and management of benign intracranial hypertension. Arch Dis Child 1998;78:89-94. 
21 Babikian P, Corbett J, Bell W. Idiopathic intracranial hypertension in children: the lowa experience. J Child Neurol 1994;9:144-9.

22 Cincirpini GS, Donahue S, Borchert MS. Idiopathic intracranial hypertension in prepubertal paediatric patients: characteristics, treatment and outcome. Am J Ophthalmol 1998;127:178-82.

23 Phillip PH, Repka MX, Lambert SR. Pseudotumour cerebri in children. J AAPOS 1998;2(1):33-8.

24 Youroukos S, Psychou F, Fryssiras S, et al. Idiopathic intracranial hypertension in children. J Child Neurol 2000;15:453-7.

25 Salman MS, Kirkham FJ, MacGregor DL. Idiopathic "benign" intracranial hypertension: case series and review. J Child Neurol 2001;16:465-70.

26 Kesler A, Fattal-valevski A. Idiopathic Intracranial hypertension in the paediatric population. J Child Neurol 2002;17:745-8.

27 Malm J, Kristenen B, Markgren P, et al. CSF hydrodynamics in idiopathic intracranial hypertension: a long term study. Neurology 1992;42:851-8.
28 Acheson JF, Green WT, Sanders MD. Optic nerve sheath decompression for the treatment of visual failure in chronic raised intracranial pressure. J Neurol Neurosurg Psychiatry 1994;57:1426-9.

29 Tamburrelli C, Salgarello T, Caputo CG, et al. Ultrasonographic evaluation of optic disc swelling: comparison with CSLO in idiopathic intracranial hypertension. Invest Ophthalmol Vis Sci 2000;41:2960-6.

30 Mulholland DA, Craigg JJ, Rankin SJA. Use of laser scanning laser ophthalmoscopy to monitor papilloedema in idiopathic intracranial hypertension. Br J Ophthalmol 1998;82:1301-5.

31 Wall M, White WN. II Asymmetric papilloedema in idiopathic intracranial hypertension: prospective interocular comparison of sensory visual function. Invest Ophthal Vis Sci 1998;39:134-42.

32 Wall $M$, George D. Idiopathic intracranial hypertension. A prospective study of 50 patients. Brain 1991;114(pt 1A):155-80.

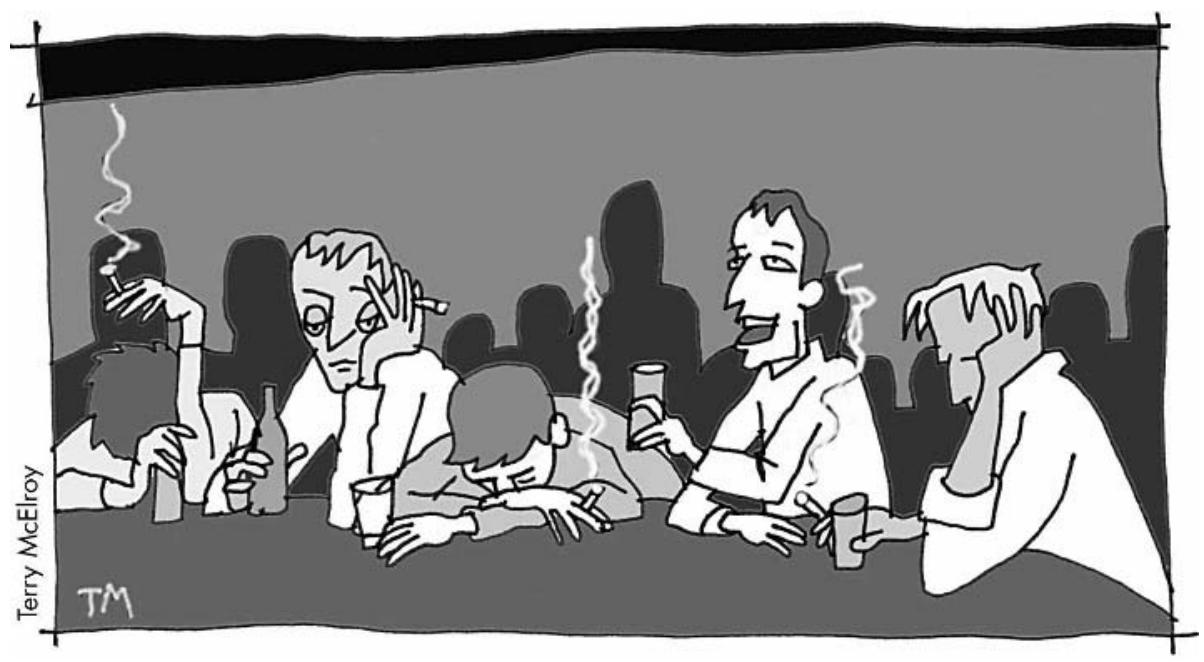

